\title{
Trying to Capture the Value of the 'Live' Conference Using an Ecological Approach
}

\author{
Hazel R. Wright and Marianne Høyen
}

\begin{abstract}
With 'live' conferences challenged by global climate and health crises, Wright and Høyen, consider what might be lost if these are ultimately replaced by online meetings, drawing on the ESREA Life History and Biography Network adult education conferences, particularly the Copenhagen meeting that they organised, to contextualise their discussion. They examine the usefulness of Bronfenbrenner's Ecological Model as a way into such a complex topic, finding that its structures supported initial thinking but were too restrictive to enable a logical but linear narrative on the value of the conference to participants, how it encourages attendance and by whom, and the ways this was examinable using publicly available sources and focused 'insider' reflection.

In a moment of epiphany, the authors understood that the conference, as a series of co-relationships, can be interpreted as a meso-level interaction, positioned between the micro-systems of everyday academic life and the macro- and external structural conditions that press down on it. Enabled to discuss how these different levels interact, the chapter considers the significance of disciplinary and knowledge boundaries and how biographical research challenges and transcends them in pursuit of the human life story, reflecting, too, on the precarious nature of the academic workplace within the neoliberal economy.
\end{abstract}

\section{Keywords}

academic conferences - Bronfenbrenner's ecological model - interdisciplinarity - life history and biography - higher education

\section{1 The Contextual Landscape}

When the content of this paper was being finalised, the entire world was being held to ransom by the coronavirus, Covid-19. As we are writing, normality is

(C) HAZEL R. WRIGHT AND MARIANNE HØYEN, 2021 | DOI: 10.1163/9789004465916_006 This is an open access chapter distributed under the terms of the CC BY-NC 4.0 License. 
on hold. Across Europe and further afield, entire countries are in lockdown, their offices, schools and entertainment centres closed. For many, even local travel is banned, and international travellers are forced to quarantine. Routine everyday activities - teaching, shopping, social contact - have to take place online or not at all for many people. These are both frightening and interesting times, the way ahead uncharted territory, the potential for radical change at a global level immense: we are repeatedly told - in the press and on social media - that life will never be the same again, that this is a 'defining historical event' (Walsh \& Millard, 2020, p. 130.) We cannot accurately predict the future, but it may be that massed gatherings, which are already a concern from an environmental perspective, will remain virtual as people fear, refuse, or are simply not allowed, to meet in large numbers in any one place. In this context, at a time when face-to-face academic conferences both local and transnational have all been cancelled, it seems particularly appropriate to consider the ecology of an academic conference and what might be missed when these take place in a virtual environment. We wonder: "What is the value of the 'live' conference as a phenomenon?" "Why (and which) academics allocate time, funding and energy to travel to meet with others to discuss their work?" We aim to examine these issues within the context of ESREA's Life History and Biographic Network (LHBN) conference around its 25th anniversary, seeking answers in relational terms, considering the interaction of influences at the micro-, meso- and macro-levels, in keeping with the ecological approach that underpins this book.

We write, having met a decade ago at a LHBN conference which took place in Geneva. Over this period, our growing familiarity with the network and developing friendship enabled us to reflect on it from both outsider and insider perspectives. Initially our experience was that of the isolated attendee. We saw the LHBN conference through independent eyes, unaware of the network's aims and intentions or its connections to the broader association, ESREA; barely aware of the work that goes on behind the scenes concerning mailing lists, conference organisation and publication. In annual steps, we progressed to chairing sessions, to scrutinising abstracts and thence to organising a conference ourselves, and subsequently a publication, choosing for both a conference in Copenhagen and an edited publication to focus on the theme 'Discourses we live by'. Thus, we write as people who have attended and organised the annual LH BN conference and with a perspective that continues beyond the experience of hosting to once again attending chiefly to present a paper and meet with colleagues. Our medium-term perspective, and our separation from the overall organisation of the Network enables an element of detachment but, nevertheless, we acknowledge the subjectivity that underpins this chapter. However, we 
are positioned differently to the established convenors - guardians of the aims and principles on which the Network is run - and the newcomers approaching it afresh; we are sufficiently familiar to have an overview.

Like most of those who support the Network we are adult educators, both accustomed to working predominately with students slightly older than the typical undergraduate, often those who seek to enter the educational professions - social educators and teachers in Marianne's case, early years educators in Hazel's. We have visited each other's country many times, met colleagues and friends and looked around the educational settings, co-devised and cotaught narrative inquiry courses for MA and Doctoral students in Denmark; eventually, working collaboratively to support each other's writing and coediting Discourses we live by: Narratives of educational and social endeavour (Wright \& Høyen, 2020) which is both extensive and diverse in its coverage. So, we felt that we should be well-able to negotiate the creation of a shared chapter but still found the chapter hard to write, perhaps, because our initial degree subjects established different epistemological expectations - Hazel was a Geographer, Marianne a Civil Engineer - and an 'ecological approach' held specific meanings for each of us that seemed difficult to apply in other contexts as we will demonstrate later. We had both studied widely to move from semi-scientific disciplines into the humanities. Marianne embraced Sociology (making a commitment to Bourdieu) and thence to work with this within Education, Hazel moved into Education where a practical and professional route took her research into Sociology and the Humanities, always in the thrall of interdisciplinary approaches. We became interested in narrative research initially as a tool to capture what people really think and feel, and like many others, found this a position that is hard to reject once adopted and (fortuitously) a sense of community within the LHBN Network. So now we will look more closely at the Network conferences but first we start by considering what constitutes a conference.

\section{$2 \quad$ What Is a Conference?}

The term conference, as conferentia meaning conversation or talk, was in use in the 16th century but derives from the Latin conferre, to bring together (Lexico, Oxford online). In its main definition it involves attendance: 'A formal meeting of people with a shared interest, typically one that takes place over several days'. As yet, in its usage as: 'A linking of several telephones or computers, so that each user may communicate with the others simultaneously', it is seen as modifier; the complete phrase being 'a conference call'. 
Even a brief comparison of these definitions identifies 'duration', 'live contact' and 'structures' as important aspects; foundational characteristics that shape relationships around 'conference'.

At this point we could simply launch into a reflective account of conference experiences but choose instead to adapt an ecological model as a way to establish a degree of structure for our discussion, believing that this may enable us to look more widely than the individual conference we organised in Copenhagen. Looking wider is important as our positioning is as 'insider reflectors' - not 'researchers' who negotiated ethical agreements - so we must keep the discussion broad to preserve the anonymity of attendees. To this end, too, the chapter draws on our personal viewpoints, remaining reflective, rather than using quotations from other attendees.

Bronfenbrenner's Ecological Model was used as a tool to assist our thought rather than a means to systemise our thinking, as it would facilitate the task of capturing the relationality between the different aspects of academic life. We are aware that with his model Bronfenbrenner (1977, p. 513) sought to heal the dichotomy between 'rigor' and 'social relevance' of concern in the 1970s, and we also seek to achieve both but from a different starting point as times have changed. Rather than using experiment and hypothesis to conduct our social analysis in a systematic fashion like Bronfenbrenner, we employed informal naturalistic observation, reflection and recall. This was supported by analysis of material that is in the public domain through the conference website (LHBN Copenhagen), and the model (theoretically) works as a focusing structure, at least as a way into examining a complex subject.

\section{$3 \quad$ Exploring Bronfenbrenner's Model}

Bronfenbrenner's model places the individual (in his case a child) at the centre of his/her world, surrounded by a set of distinctive spheres of influence or levels (Bronfenbrenner, 1981). In the model we find four systems (the micro-, meso-, exo- and macro-) relating to the individual child who is seen as an active participant in the process of development, engaged in continually adapting to the environment which is continuously changing; the notion of time conceptualised as a surrounding chronosphere. In our version of the ecosystem, the conference attendee occupied the central position and we were mindful that this was an adult whose interactions with and in the world would be constituted differently.

Our context for using Bronfenbrenner's model is the Copenhagen conference, and we worked as he did from micro- to macro-level, driven by our shared 
concern that each LHBN conference ends with uncertainty for the future, particularly around where we might meet the following year. This initial application was not too taxing. As Bronfenbrenner's focus is developmental, his underlying interest is in the transitions as the child moves from the micro- to other systems, his spheres are populated with centres that serve children, like preschool and day-care settings, orphanages and hospitals (Shelton, 2018). In our initial discussion we, too, follow this directional pattern needing to look at microsystems before mesosystems, and to establish the way that the exosystem influences the macrosystem. We use the spheres to identify the different layers of influence that may impinge on the conference attendees who sit at the core of our model. For our purposes, it is the specification of the different levels of influence that matters, the relationships they enable and constrain and conversely the constraints and affordances they establish. We are mindful, too, that each conference will present a unique set of affordances to those who attend it but speculate that these are diminished when a conference goes online and loses its sense of place, its tangibility, the 'colour' that emanates from belonging in the real world. But, here, we are actually working to reduce difference, for in drawing out the aspects that populate each sphere we are seeking to simplify complexity into sets of influences.

The micro-level for the attendee has two aspects: the patterns, roles and relationships relating to the home university to which s/he belongs and those that relate to the actual conference. In terms of the home university we would position colleagues and managers as important and see their relationships with the attendee in terms of practicalities: teaching schedules, willingness to provide cover for absence and to allocate elements of budgets to finance the attendance, the extent to which they view a particular conference, topic or staff member as worthy of support. Many of these are potential barriers to attendance. Within the conference there are relational issues around the location (is it attractive, is there affordable accommodation, are the organisers helpful in answering questions by email), relationships with colleagues from the home university (peers, supervisors, those of similar or different academic status) and with the other conference delegates whose names may be publicised in advance and with whom the attendee may or may not already have a relationship. Notably those who supervise doctoral students bring a steady stream of new researchers into the Network demonstrating how contact in the home university can translate into relational issues within the conference. Conversely, a conference can also represent an escape from everyday connections. It is only since Hazel became an Honorary Fellow that she has invited colleagues and students along. When she worked full time, she preferred to attend alone to meet new people. Marianne, too, came by herself prior to 
becoming conference host when departmental support was both useful and achievable. We wonder, does the LHBN attract academics seeking new contacts and sufficiently independent to 'come solo'? For we recognise now that, alongside those who attend with supervisors, there are many who travel alone. And looking back to those early experiences as a newcomer we recall how, despite the welcome, there was a sense that everyone knew everyone else and of an inner clique of people with years of shared experiences that bordered on the exclusionary. Seeking to belong, we were aware, too, that there were no formal structures to facilitate this, no committee to join, no posts to volunteer for, no tasks to take on short of offering to host a conference; all points we will return to later.

The meso-level holds the interrelations among two or more settings. This is a little confusing as 'settings' more commonly means physical spaces, but Bronfenbrenner's examples are conceptual - family, work and social life. The meso-level is where aspects of individuals' lives begin to mesh, forming a web of relationships that may combine or conflict, thereby supporting or constraining the individual's development and it is this personal web of connections that constitutes a unique mesosystem. If we claim that for conferences generally, groups of researchers within a network, the conference convenors, academic publication systems, and the conference hosts are examples of microsystems, then the links they make with the individual and with each other constitute the mesosystem, with them remaining discrete entities. LHBN provides a gateway to a broader meso-level for those who seek this, providing an entrée to other subject networks within the broader ESREA framework, and the parent society that offers opportunities to set up a new network, to join the central organising committee, and to access further publication opportunities in books and the European Journal for Research on the Education and Learning of Adults (RELA), too.

In the exosystem we find structures/settings that indirectly affect the individual attendee. Our suggestion for populating this level consists of discursive settings (discourses understood as talk and practice), namely: the political frameworks shaping research and education; funding systems; and the media as gatekeepers to success, whether as reporters of events or publishers of academic material. These arenas differ from country to country as does the extent to which they influence 'what it is to be a researcher now' and hence affect the attendee. As it is based in Western Europe, even though the emphasis varies across nations, the conference is shaped and constrained by prevalent neoliberal forces. Funding is a major consideration and also the 'pressure' for academics not only to research and publish but also to teach to higher and higher standards. LHBN members are not exempt from such expectations and can 
find it difficult to get their universities to recognise the value of small-scale research and 'stories' when others are solving global problems or serving the local community.

It is the macro-level, which holds the culture, value systems and underlying ideology that shapes the other spheres and although globalisation is continually challenging difference, this also varies according to country. Arenas here include the labour market (especially the academic job market), overarching disciplinary discourses, and the predominant knowledge paradigm. These arenas were once straightforward but are continually changing in today's globalised society (Lyotard, 1984; Nowotny et al., 2001) where they are increasingly affected by changes in the exosystem (the Covid-19 pandemic being an extreme example). Within a context - ours being academia - these arenas rarely function in isolation. In terms of conference attendance, attendees must navigate within these framings and position themselves within the possibilities that are available. They must cope directly with the consequences of the macrolevel systems acting on the lower (meso) level, making negotiation even more complex. Academic culture is under pressure, our value systems challenged by structures in the exosystem. LHBN conference attendees annually face these challenges. For us, as authors, the challenge was more structural, one of trying to simplify real-world complexity to align with a theoretical model.

For then we struggled with the model. It served to support our thinking at a theoretical level, enabling us to identify different influences affecting and affected by the conference attendee, but however we approached it, working outwards or, even worse, trying inwards, it became unwieldy and restrictive as a format to shape discussion. We realised that, in part, the problem is the centring on an individual when in reality all the influencers affect each other, sometimes directly, sometimes filtering through other influences. We had followed Bronfenbrenner in actively seeking to place individuals at the centre of their own lives, to set those lives in context, and to promote agentive behaviour but this was at variance with our understanding that interactions are multiple and multi-directional. Trying to apply the model in real life clearly highlighted this conflict, identifying the model's limitations. Because of the complexity of interactions, to shape our discussion to address each level in turn would lead to much unnecessary repetition and artificially constrict the discourses.

Only at this point, about to give up on the ecological model, did we grasp an important point. In an 'aha' (Mezirow, 1975) or epiphanic moment (Denzin, 
2001) we realised that a conference is a mesosystem as it only exists in the coming together of disparate elements - the interrelation of people, places, papers, plenaries, social events, in all their different ways. Our interpretation of the mesosystem and our earlier analyses had whispered this, but we hadn't listened carefully enough! Our editors alluded to it, too, but in the context of a longer trialogue on our first draft where it remained unread, lost in words. But suddenly we knew it, without knowing how. To explain thoroughly (if we could) would be to reject the notion of 'aha' moments and epiphanies for the causes of that transformative moment when you 'just know something' are essentially elusive. For Marianne the moment equates with a sense of enlightenment, for Hazel this conviction is also embodied as an inner calm, a feeling that she is fully in the present moment; for both it signifies a puzzle solved even a new understanding that was unsought but is now irreversibly known.

So, Eureka! Our discussion of actual conferences, and specifically the one in Copenhagen sits within the meso-level but our further discussion needs to follow its relevant themes, with only casual reference to levels when we bring in specific key influencers. So, with structural problems to some extent addressed, we can turn at last to our core interest in what makes going to a 'live' conference valuable?

We look now more closely at the LHBN conferences, and specifically at the Copenhagen one when detail is useful. We will look briefly at aspects that span the levels - ever mindful that hostile conditions in the exosystem (like pandemics) react on practices at the macro-level (like lock down), together creating challenges at the micro-level (like staying home) - but the main focus will be on the meso-level, particularly those things that serve to make the conference hospitable. We gave up trying to deal with levels and their content as distinctive entities - that was useful only at a theoretical level - and accepted that it is the relationality between entities and across levels that matters, mindful that Bronfenbrenner was trying to demonstrate connectivity and at least point to the complexity of causality.

Under neoliberalism (which we consider to be a facet of the exosystem), academics are increasingly expected to cope with a heavier workload, to teach more students for longer periods, and to publish regularly; all factors that potentially lead to more standardised approaches and less space for creativity. We struggle with these expectations - Hazel even moved from paid to honorary 
status to reduce their impact - and find they make it harder to 'get away' anywhere. Yet we find the time to come to 'live' conferences and so do those others who attend. Perhaps this time pressure is even reflected in the abstracts submitted to the Copenhagen conference. Researchers choose their methods to suit their projects but quite possibly the predominant use of biographical and narrative methods over full life histories is a sign that researchers have limited time available to carry out their work and need to use quicker methods in order to publish more frequently for career progression in a competitive labour market. We are not suggesting that this is 'quick and dirty' (Petre \& Rugg, 2010, p. 70 ), only that evaluative regimes favour speed and quantity, and data that enables generalisation. It may even be that biographical and narrative methods are too slow. Collecting and interpreting such data is a time-consuming process and this is reflected in the costings that accompany bids for funding and maybe makes them uncompetitive. Often funded research is required to have a social 'impact', too, but we found this to be evident in most papers whether or not the research was funded. Quite possibly, in educational and caring disciplines, professional and client interaction makes social impact inevitable.

Abstracts to the Copenhagen conference reflected the adult educational theme of the Network and most were found to pursue themes within the disciplines of education, social work or health. These are all non-traditional disciplinary areas that sit within the public services sector and themselves draw material from other disciplines (facets of the macrosystem). These are sectors, too, that operationalise policies devised at macro-level as services for the individual, demonstrating that biographic methods serve a useful function in establishing people's views. In talking freely, end-users provide insights that relate to 'how' rather than simple 'what' questions, revealing the shortcomings or benefits of social provision for those to whom it matters.

Most contributors had an affiliation to a specific disciplinary area, whether traditional or more recent, and would have encountered its inherent value systems as exemplified by our difficulties in reinterpreting 'ecological approaches'. However, it is likely that they had also looked beyond disciplinary boundaries to achieve the broader understanding of the human required for work with life stories. In this way, biographical research serves to disrupt traditional knowledge boundaries, to avoid 'fragmentation' (West, 1996) of lives by disciplinary boundaries. In conversation, attendees appeared to privilege inter- or transdisciplinarity as a more compelling and inclusive way of researching. In this way, the LHBN conference could be seen as innovative, and this is self-perpetuating as its 'live' nature provides opportunities to learn from colleagues in other disciplines, to work co-operatively with them and to make the first steps beyond the security of the disciplinary boundary. Thus, it follows ecological 
principles of constant and harmonious adaptation. Attendees may not fully anticipate this, but it is clear from chatting to them at this and subsequent conferences that once they have experienced it, they appreciate the chance to meet with others who also work across disciplines. This sense of shared values is not always easily found within the traditional disciplinary structures of the university; in education we are privileged to have some learning in common but may still reside in separate subject silos, utilising a previously acquired qualification set.

The conference abstracts also drew attention to value systems through their content. Many dealt with the consequences of external constraints on working life - cuts in educational budgets, the narrowing possibilities to care properly for those for whom we are professionally responsible, the effects of external evaluation criteria of various sorts. Harking to the exosystem, the label neoliberalism appeared in several titles as well as within abstracts. That many attendees were insider researchers showed clear links between what is happening externally and concerns for how this affects individual sectors in education, social care and health. Abstracts also reflected significant events in the real world, migration, for example. This was a commonly studied topic, individually but also within larger funded projects, demonstrating the importance attached to this issue at higher levels but also the significance of funding (part of the exosystem) in shaping what happens elsewhere. There are definite linkages confirming that the component elements in a system affect each other, supporting an ecological interpretation.

Examining the abstracts as a group, also provided a snapshot of 'who' attends the conference. At a number of conferences, we have been part of discussions about the nature of the membership and whether it is sufficiently diverse, again a reflection of the conferences' values. Our records for Copenhagen enable us to comment on this but we recognise that the picture may be very different in other places in other years. In Copenhagen, the majority of the abstracts were from the English-language world ( $47 \%$ ), with a high percentage from women $(71 \%)$. It was also clear that although many of the researchers had a university affiliation a considerable number were either at an early stage of their academic career or the opposite, close to retiring officially $(61 \%)$. The largest national group were from the UK $(35 \%)$, followed by Italy $(11 \%)$ and then Denmark (6\%), the home of the conference this year, demonstrating that the network still has work to do in extending its geographical cover and participant range. The remainder were individuals from other European countries and a number of regular attendees from further afield who often extend their visit to include holiday, maybe with their partner. We have no means of accurately establishing class or ethnicity but know from the conference itself that 
some openly claim working class (or other) origins as a 'badge of honour', yet very few identified as, or were identifiable as, belonging to an ethnic minority. There was a significant gender imbalance, a marked Anglocentric skew for a society purporting to be pan-European, and attendees were predominantly white, socially mobile working-, if not yet middle-, class. More unusually, the age of attendees was polarised, early career researchers and a significant proportion of elder academics. Overall, the attendees did not represent the diverse group that we, as that year's organisers, were keen to attract.

The abstracts fitted into one of four categories and it is tempting to speculate that these related to career stages. Many were personal projects pursued as part of a higher education qualification, usually a doctorate, and these clearly aligned with early career researchers. Others were personal projects discussing work that the individual had pursued over a considerable period of time, and here the timeframe suggests mid-career status. In a third category were a small number of larger projects with groups of researchers working together over a number of years, usually supported by external funding from the EU or other official establishments or administrative bodies, for example within health. We have seen that it is often the experienced academics with established contacts who manage to acquire such funding. The last category comprised a significant number of small-scale individual projects possibly devised and carried out to provide material specifically for the intended conference presentation; others were retrospective reflections on projects carried out earlier. Some of these we know to be the work of retired individuals who no longer command the resources to undertake larger-scale projects.

Despite its lack of refinement, our overview of the content of abstracts may partly explain a problem that the Network regularly faces but so far has managed to overcome, namely a shortage of conference hosts (and consequently, but of secondary importance, difficulty in finding new locations). The neoliberal expectation that members of educational establishments will be directly charged to use their own premises and facilities has surely exacerbated matters but the polarised membership in terms of age and career status may also play a part. We wonder why the Network attracts so few mid-career researchers or lecturers, those with established positions who might be able to host new conferences? Perhaps they judge a bigger conference to better meet their needs. Maybe they are forced to pursue more quantifiable topics - biographical and narrative research, being interdisciplinary but at a personal rather than team level, may be difficult to submit to national evaluations. Perhaps they are too busy teaching or working on externally funded projects to get to conferences not held during the long vacation, constrained by fixed budgets that restrict international travel or make it more difficult. It is also possible that 
they are being replaced by cheaper, digitally, competent, more malleable(?) younger staff in line with the neoliberal agenda. We can only speculate but see this last fear reflected in Standing's (2011) claim that the precariat (those with unstable working conditions, such as hourly paid lecturers) now dominate the academic labour market. Finance features significantly in the issues raised here and certainly at the micro-level it had a direct influence on attendance. Some $25 \%$ of people who submitted abstracts later cancelled and many cited lack of funding as the reason for doing this, but, inherently, their withdrawal prevented further explication.

As adult educators, we wonder whether higher-level value judgements about useful methodologies are at play here. Despite the very different circumstances, are there echoes of the nineteenth century call for 'really useful knowledge' (Johnson, 1988)? We also question whether the conference could do more to support its own continuity. Earlier we talked about the lack of structures to enable a newcomer to find a niche (another term appropriated from ecology) but finding ways to do that whilst respecting the central role of the convenors may be a challenge. To threaten the Network's established practices could be counter-productive, and the fluidity of the 'gatherings' we hold in place of 'meetings' is important. But the convenors have now started to invite people to volunteer to take on specific tasks to spread the workload beyond themselves, and a prudent formalisation of such roles, could afford opportunities to those who want to commit. Such volunteers might also share the work of organising a conference with sensitivity, so that people who attend alone and lack a ready-made network of colleagues with insider knowledge to support this task, could be assured of useful assistance. At present, it is possible that the mid-career researchers keen to broaden their external influence and enhance their CVs, more easily find a niche elsewhere. Perhaps we need to find ways to harness the energy of those who can 'do more' to support the network practically. These are suggestions but not answers, and we should continually probe for hidden discourses and question whether the appearance of equality, the lack of other roles, masks a reluctance to share power?

To return to conference hosts, we have to hope that the shortage is a temporary problem, just a case of waiting for some of these early career researchers to become established, for our observations show that most of those who do attend value the biographic method highly and we know that this is a method increasingly acknowledged to be important (O'Neill et al., 2015), despite its time demands and costliness. As an icebreaker at the Copenhagen conference, we invited attendees to form small groups to discuss why they favour narrative research methods and how they came to use them. Unfortunately, we did not seek permission to quote their comments directly, but we did note the depth 
of their commitment and, often, the passion with which they talked about this. Clearly the methodology itself, working with biographical materials, is an intrinsic reason for attending the LHBN conference, but so is the chance to hold such informal and personal conversations around a shared interest.

To specifically address our main question about the value of the 'live' conference, it is self-evident that for people to attend a conference the benefits and attractions of doing this must outweigh the reasons not to bother and no doubt motivators differ. Some conferences are hierarchical with elite committees keeping themselves apart from the masses, setting aside significant funds to attract eminent keynote speakers. Attendance at these is prestigious and there is always the possibility that your work may be noticed by someone important. In contrast, LHBN eschews displays of status, deliberately avoiding the use of academic titles on name badges and documentation, avoiding expensive keynote speakers and striving for a semblance of equality even though we usually know the professors from the doctoral students. Other conferences attract attendees through their choice of venues, visiting a new 'place of interest' each year. Hazel used to attend a significant conference that never fails to locate in a popular tourist location, until she became disenchanted by its size, the consequent difficulty in finding proximate accommodation and, finally, a decision to offer many established presenters a poster slot in order to accommodate the numerous new participants. Neoliberal values with regard to finance and status resonate here but also, disciplinarity: those colleagues for whom the focus is more 'central' continue to attend.

In contrast, the locations of LHBN conferences are determined by which members are able to access suitable but non-costly venues and willing to be hosts. To encourage attendance LHBN tries to minimise conference costs, offering reduced rates for doctoral students, advising on low-cost accommodation and providing as many meals as possible. Often, especially in more expensive locations, the academics and their colleagues themselves manage the catering. In Geneva, members brought in food, in Magdeburg and Turin we were fed informally on campus, in Bergen we were invited in small groups into colleagues' homes for a meal 'en famille'. Similarly, conference dinners are held in interesting places rather than formal restaurants: in the old bath's changing huts on Lake Geneva, at the communal diner in the hippy colony of Christiania in Copenhagen, in a historic boathouse in Bergen. Pre-conference events are informal and low cost too, walking or bus trips around the city we are in, visits to local landmarks - to the ruined abbey and cathedral archives in Canterbury, for example.

By popular request we now build 'free time' into the programme so that there is time to shop, to visit galleries or museums, to attend local events (a concert 
in Bergen, evensong in Canterbury cathedral), to socialise in small groups or go to a pub or café in a big one, to meet and plan shared ventures with colleagues whose interests overlap with your own. This informality enables people to relax and make friends, creating a sense of community within the Network that would be difficult to establish in an online conference. In turn, genuine friendships lead to working relationships that really 'work', making it possible to survive the ups and downs of collaborations later managed at a distance. In contrast, we all know other conferences where the papers are presented continually from an early hour until late into the evening. Last year Marianne and Hazel arranged to meet up at a different European conference. This was much larger than LHBN's, catering for a single-discipline, and aspiration and inspiration were clearly focal. It attracted many mid-career researchers suggesting, as might be expected, that for them perceived career opportunities influence conference attendance. It was an interesting and stimulating event but very intense. We found it did not even schedule a lunch break, one had to decide which event to miss to eat at mid-day. It is hard even to find your existing friends at such an event, even harder to make new ones, but this can be an important step in developing a collaborative partnership for future work, making all conference attendance potentially valuable - an insight that management may find hard to grasp!

A Network with a 'live' conference like LHBN, in creating a safe space for sharing and co-operation, may also serve as a site of resistance. The social contact of the 'live' conference offers opportunities to find others to support your cause or find a cause you wish to join, the chance to co-publish material rather than stand alone, to petition collectively for policy or other change. Not least it offers chances to 'test the water', to find out discretely if the problems you are encountering are commonplace or exceptional, to share solutions or ways to ameliorate the undesirable, perhaps simply to empathise. We remember the relief in finding that other academic colleagues were struggling with overwork; the sense of perspective gained from finding that Iberian colleagues were even worse off, facing pay cuts as well as increased workloads. We hope they found some benefit in our sympathy and doubt that a digital meeting would offer such opportunities to 'share' and reflect on the realities of academic life. Yet this is important for an academic's sense of wellbeing.

Thus, through valuing equality, informality, sociability and, importantly, by promoting a methodology that is intrinsically attractive, the LHBN conferences encourage attendance. Structurally - by offering free time, safe spaces and shared experiences, chances to get to know people properly and make friends, alongside the normative agenda of papers, plenaries, workshops and a dinner - our conferences are relaxed and welcoming even for newcomers. 
There is a dark side to this - informality can leave people unsure what to do, close relationships can mean that people disagree and fall out (and we have some experience of picking up the pieces here), built in free time can leave some people wondering whether they are getting their money's worth - but we deal with it as individuals and as a collective. By setting out our values we open the conference to criticisms that we fail to practice what we preach - but short-term challenges, if addressed, can ultimately strengthen the Network. Twenty-five years on, it is still flourishing and attracting new members to its 'live' conferences. Many return year after year; confirmation that they deem the conference to have value. Whether this will continue under the post-pandemic 'new normality' remains to be seen.

\section{References}

Bronfenbrenner, U. (1977). Toward an experimental ecology of human development. American Psychologist, July, 513-531. https://psycnet.apa.org/doi/10.1037/ooo3o66X.32.7.513

Bronfenbrenner, U. (1981). The ecology of human development: Experiments by nature and design. Harvard University Press.

Denzin, N. K. (2001). Interpretive interactionism (2nd ed.). Sage. https://dx.doi.org/ $10.4135 / 9781412984591$

Johnson, R. (1988). 'Really useful knowledge' 1790-1850: Memories for education in the 1980s. In T. Lovett (Ed.), Radical approaches to adult education: A reader (pp. 3-34). Routledge.

LHBN (Copenhagen). (2017, March 2-5). Discourses we live by. ESREA/LHBN Conference, Copenhagen. Retrieved June 6, 2019, from http://conferences.au.dk/esrealhbnzo17/

Lyotard, J.-F. (1984). The postmodern condition: A report on knowledge. Manchester University Press.

Mezirow, J. (1975). Education for perspective transformation: Women's reentry programs in community colleges. Center for Adult Education, Teachers College, Columbia University.

Nowotny, H., Scott, P., \& Gibbons, M. (2001). Re-thinking science: Knowledge and the public in an age of uncertainty. Polity Press.

O'Neill, M., Roberts, B., \& Sparkes, A. C. (2015). Advances in biographical methods: Creative applications. Routledge.

Petre, M., \& Rugg, G. (2010). The unwritten rules of PhD research (2nd ed.). Open University Press.

Shelton, L. (2018). The Bronfenbrenner primer. A guide to develecology. Routledge. https://doi.org/10.4324/9781315136066 
Standing, G. (2011). The precariat: The new dangerous class. Bloomsbury Academic.

Walsh, Fergus talking with Rosie Millard. (2020, May 9-15). I got in my car and cried. Radio Times.

West, L. (1996). Beyond fragments: Adults, motivation and higher education, a biographical analysis. Taylor \& Francis.

Wright, H. R., \& Høyen, M. (2020). Discourses we live by: Narratives of educational and social endeavour. Open Book Publishers. https://www.openbookpublishers.com/ product/1110 